\title{
COAGULOPATHY AND COVID-19: A REVIEW FOR MEDICAL PRACTICE.
}

\author{
Estrella Porter Jorge ${ }^{1}$, Del Castillo Arellano Jaime ${ }^{1}$, Añazco Villarreal Diego ${ }^{1}$, Ayala Mullo Juan ${ }^{1}$, Badillo Llerena Alejan- \\ dro' ${ }^{1}$ Balcazar Medrano Dayanara', Bolaños Romero Daniel', Cañizares Quisiguiña Stalin ${ }^{1}$, Carrera Barriga Gabriela', Di \\ Stefano Pelizzo Marco ${ }^{1}$, Espinosa Maza Jorge ${ }^{1}$, Espinosa Proaño Isabel ${ }^{1}$, Guamán Maldonado Lucia ${ }^{1}$, Guijarro Falcon \\ Katherine ${ }^{1}$, Guzmán Cerda Paola ${ }^{1}$, Iturralde Elena ${ }^{1}$, Moncayo Intriago Ruben ${ }^{1}$, Montalvo Silva Paola ${ }^{1}$, Moya Quitto Gusta- \\ vo ${ }^{1}$, Muhammad Mendoza Iqrah ${ }^{1}$, Noboa Salgado Gabriela ${ }^{1}$, Ortiz Salazar Doménica ${ }^{1}$, Puertas Ruiz German ${ }^{1}$, Pullas Man- \\ tilla Tatiana ${ }^{1}$, Salazar Chuquimarca Cinthia ${ }^{1}$, Sosa Cifuentes Daniela ${ }^{1}$, Suarez Aguirre Fabian ${ }^{1}$, Vinueza Erazo Denise ${ }^{1}$, \\ Zambrano Real Esteban ${ }^{1}$, Zarate Cazorla Susan ${ }^{1}$, Zurita Salvador Danna ${ }^{1}$, Di Stefano Ciabatella Marcos ${ }^{1,2,3 *}$
}

DOI: $10.48018 /$ rmv.v32.11.5

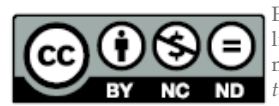

artículo está bajo una licencia de Creative Commons de tipo Reconocimiento - No comercial - Sin obras OPEN ACCESS derivadas 4.0 International.

1 Universidad San Francisco de Quito - USFQ. Colegio Ciencias de la Salud. Escuela de Medicina. Quito Ecuador.

2 Hospital Solón Espinosa Ayala - SOLCA: núcleo Quito. Médico del servicio de Hematología/Citometría/ Biología Molecular. Quito - Ecuador.

3 Hospital de los Valles. Médico del servicio de Hematología. Quito - Ecuador.

ORCID ID:

Estrella Porter Jorge

orcid.org/0000-0001-9773-661X

Del Castillo Arellano Jaime

orcid.org/0000-0003-4922-0066

Añazco Villarreal Diego

orcid.org/0000-0003-1829-7001

Ayala Mullo Juan

orcid.org/0000-0002-4484-5908

Badillo Llerena Alejandro

orcid.org/0000-0001-6264-3333

Balcazar Medrano Dayanara

orcid.org/0000-0003-4661-1109

Bolaños Romero Daniel

orcid.org/0000-0003-1505-3247

Cañizares Quisiguiña Stalin

orcid.org/0000-0003-4706-862X

Carrera Barriga Gabriela

orcid.org/0000-0002-1627-970X

Di Stefano Pelizzo Marco

orcid.org/0000-0002-5950-5340

Espinosa Maza Jorge

orcid.org/0000-0001-5120-6082

Espinosa Proaño Isabel

orcid.org/0000-0002-6060-344X

Guamán Maldonado Lucia

orcid.org/0000-0001-8490-5728

Guijarro Falcon Katherine

orcid.org/0000-0002-5152-4272

Guzmán Cerda Paola

orcid.org/0000-0002-6729-2816

Iturralde Elena

rcid.org/0000-0003-3552-4157

Moncayo Intriago Ruben

orcid.org/0000-0002-8687-7799

Forma de citar este artículo: Estrella J, Del Castillo J, Añazco D, Ayala J, Badillo A, Balcazar D, et al. Coagulopathy and COVID-19: a review for medical practice. Rev Med Vozandes. 2021, 32 (1):

\section{Abstract}

In December 2019, an outbreak of a new coronavirus disease (formally known as COVID-19) was first reported in Wuhan, China, and soon spread around the world. On March 11, 2020, COVID-19 was declared as a pandemic by the World Health Organization (WHO). So far, COVID-19 has proven to be a disease with multiorgan involvement, affecting the hematological system as well. Patients with COVID-19, especially those with moderate to severe disease, frequently experience a coagulopathy associated with a high incidence of thrombotic events, which leads to poor outcomes. The pathogenesis of COVID-associated coagulopathy (CAC), is not fully understood yet, although the host inflammatory response to the infection appears to be a crucial element in the development of CAC. IL2, IL-6, IL7, G-CSF, PI10, MIP1, and TNF alpha, among other molecules, act as proinflammatory cytokines that stimulate endothelium damage and alter the coagulation homeostasis. CAC usually manifests as venous thromboembolisms (VTE). While bleeding can also occur, it is a rare form of presentation. Inpatients with COVID-19 must receive thromboprophylaxis, mainly with low-molecular-weight heparin (LMWH); unfractioned heparin can be accepted under certain circumstances. Patients with a diagnosis or high suspicion of VTE should receive the complete doses of anticoagulation treatment and must continue on it for at least three months. Recommendations regarding prophylaxis and treatment may vary among institutions and countries. There is not clear evidence for the regular use of antiplatelet therapy in patients with COVID-19. This review will provide key insights regarding the pathophysiology, clinical manifestations, diagnosis and treatment of COVID-19 and its associated coagulopathy.

Palabras clave: COVID-19, coagulopathy, SARS-CoV-2, coagulation, thrombosis.

\section{Resumen \\ COAGULOPATÍA Y COVID-19: UNA REVISIÓN PARA LA PRÁCTICA MÉDICA}

En diciembre de 2019, un brote de una nueva enfermedad formalmente conocida como COVID-19 se informó por primera vez en Wuhan, China, y pronto se extendió por todo el mundo. El 11 de marzo de 2020, el COVID-19 fue declarado pandemia por la Organización Mundial de la Salud - OMS. Hasta ahora, el COVID-19 ha demostrado ser una enfermedad con afectación multiorgánica, afectando también al sistema hematológico. Los pacientes con COVID-19, especialmente aquellos con enfermedad de moderada a grave, experimentan con frecuencia una coagulopatía asociada con una alta incidencia de eventos trombóticos, lo que conduce 
Montalvo Silva Paola orcid.org/0000-0002-6766-1271 Moya Quitto Gustavo orcid.org/0000-0002-5948-4367

Muhammad Mendoza Iqrah

orcid.org/0000-0002-2278-872X

Noboa Salgado Gabriela

orcid.org/0000-0002-7439-2532

Ortiz Salazar Doménica

orcid.org/0000-0002-4646-2361

Puertas Ruiz German

orcid.org/0000-0002-7535-3842

Pullas Mantilla Tatiana

orcid.org/0000-0001-53156170

Salazar Chuquimarca Cinthia

orcid.org/0000-0002-5439-256X

Sosa Cifuentes Daniela

orcid.org/0000-0002-0567-339X

Suarez Aguirre Fabian

orcid.org/0000-0001-9361-050X

Vinueza Erazo Denise

orcid.org/0000-0002-4664-822X

Zambrano Real Esteban

orcid.org/0000-0002-6698-9056

Zarate Cazorla Susan

orcid.org/0000-0002-5670-4547

Zurita Salvador Danna

orcid.org/0000-0002-4813-0491

Di Stefano Ciabatella Marcos

orcid.org/0000-0002-6749-6261

*Corresponding author: Di Stefano Ciabatella Marcos

E-mail: distefano.mt@gmail.com

\section{Article history}

Received: 6 - Jan - 2021

Accepted: 19 - Feb - 2021

Publish: 01 - Mar - 2021

Conflict of interest: All authors declared that there are no conflicts of interest.

Financial disclosure: The authors have no financial relationships relevant to this article to disclose.

Authors' contribution: All the authors contributed in the search selection of articles and writing. All the authors reviewed and approved the final manuscript.

\section{Introduction}

In late December 2019, a cluster of cases of pneumonia was first documented in Wuhan, Hubei Province, China. These pneumonia cases from unknown etiology were originally tracked to patients who visited a wet seafood market where other exotic wildlife animals were sold as well.(1) Eventually, a novel coronavirus was identified as the causative agent of the disease: named SARS-CoV-2, this is a simple RNA type beta-coronavirus(2). At first, the disease was known as "Wuhan pneumonia", since it was limited to people who lived in nearby areas or who worked in that market, and then renamed as COVID-19(3). Since its discovery, the virus has been causing a rapid and uncontrolled spread worldwide, leading to outbreaks in almost every country, which has resulted in more than 114 million confirmed cases, and around 2.5 million deaths, according to the CSSE at Johns Hopkins University. To this day, COVID-19, declared a pandemic by the WHO in march 2020(4), is still spreading around the globe and due to its lack of specific treatment and widely available vaccination campaigns in a majority of countries, this disease stills represents a big threat to public health(5).

COVID-19 is a not-only-respiratory but a systemic disease, with a range of clinical manifestations, ranging from no symptoms at all to critical illness and death ${ }^{(6)}$. The most common symptoms include fever, cough, sore throat, malaise, headache, muscle pain, nausea, vomiting, diarrhea, loss of taste and loss of smell(7). According to the $\mathrm{NIH}$ from the United States of America, COVID-19 severity can be classified as follows: asymptomatic (individuals with no symptoms at all), mild disease (individuals who have any of the signs and symptoms of COVID-19 but who do not present with difficulty in breathing or abnormalities in chest imaging), moderate illness (individuals who have evidence of lower respiratory compromise during clinical assessment or evaluation by imaging 
techniques, and who have SpO2 $294 \%$ on room air at sea level), severe illness (for individuals with SpO2 <94\% on room air at sea level, $\mathrm{PaO} 2 / \mathrm{FiO} 2<300 \mathrm{mmHg}$, respiratory rate $>30$ breaths per minute, or lung infiltrates compromising $>50 \%$ ) and critical illness (individuals who have either respiratory failure, septic shock, and/or multiple organ dysfunction) ${ }^{(8)}$.

Coagulopathy, an alteration in the normal homeostatic state of the coagulation system, appears to be related with COVID-19, especially to patients who develop moderate to critical COVID-19 cases $^{(9)}$. Several abnormalities related to coagulation markers have been widely reported in patients hospitalized with COVID-19, who are the ones who present at least moderate disease. In fact, coagulopathy is one of the most significant prognostic factors in patients who have COVID-19, as it is related with poor outcomes(10). The COVID-associated coagulopathy, CAC, is not yet fully understood, but it has been associated with specific markers, such as elevated D-dimer and fibrinogen levels, as well as with thrombocytopenia, which tends to be mild, and with modest prolongations of prothrombin time (PT) or partial thromboplastin time (PTT), if any, making it different to other coagulopathies associated to infection, such as disseminated intravascular coagulation(11). Considering that CAC can affect as much as $20 \%-30 \%$ of patients with severe disease, reaching almost $49 \%$ prevalence in those admitted to ICU (12), it is necessary to understand this clinical aspect of COVID, in order to enhance a more comprehensive clinical management. For this reason, this study aims to show the key aspects of the CAC, including its pathophysiology, diagnosis, evaluation and treatment, based in the state of the art and the information available to this day.

\section{COVID-19 and coagulation}

COVID-19, the relatively new disease caused by the SARS-COV-2 virus, has been proved to be associated with microthrombi formation in lung and other tissues (13). As a result, the term CAC, COVID-associated coagulopathy, is now being used for defining mechanisms associated with coagulopathy in COVID-19 patients ${ }^{(14)}$. There is still controversy regarding the specific pathways involved in its pathogenesis ${ }^{(15)}$. It is unclear whether it relies on current known molecular mechanisms in clot homeostasis or if the infection triggers a different reaction. For instance, SARSCov2 may enter endothelial cells through the ACE2 receptor stimulating the coagulation process ${ }^{(13)}$. Apparently, the infection also causes a cytokine storm in certain patients, characterized by the release of IL- 6 , IL-1 $\beta$, TNF- $\alpha$, granulocyte colony stimulating factor (G-CSF), and interferon $\gamma$-inducible protein (IP10) which ultimately enhance the expression of P-selectin, VWF, TF and VEGF in the endothelial cells ${ }^{(16)}$. As a result, vessels proliferate and platelets, which have increased in number due to trophic cytokines, bind through adhesion molecules, starting the coagulation cascade ${ }^{(17)}$.

However, it has also been proposed that, in contrast to other virus, the interaction of SARS-CoV-2 within the coagulation cascade may not be as important when compared to other factors in the clot homeostasis(18). This may interpret endothelial damage as a result rather than a cause, as it is well known that hyperviscosity, which is present in some critical patients, can cause endothelial damage(15). The resultant systemic inflammatory response might also be independently associated with thrombo-inflammation(16). All in all, it is very likely that hypercoagulation in the COVID-19 context has a multifactorial origin, but because of discordant data, more research is still needed to provide an accepted and fully proven pathogenic mechanism.

\section{Pathophysiology}

\section{The liberation of cytokines as an initial in- flammatory process}

From a pathogenesis point of view, COVID-19 triggers an unrestrained cytokine production, which contributes to the severity of the disease ${ }^{(19)}$. To start with, SARS-CoV-2 is recognized via surface receptors ACE2 and TMPRSS2. Its detection induces pyroptosis of the infected cells when viral PAMs are recognized by PRRs. Furthermore, the hosts cells destruction generates DAMPs, such as ASC and nucleic acids oligomers, which will be identified by neighboring alveolar macrophages along with endothelial and epithelial cells ${ }^{(20)}$. Subsequently, IL6 will be produced, orchestrating further response. IL6 can activate two possible pathways, cis and trans signaling. Cis activation will induce both innate and acquired immune response, promoting migration of $B$ and $T$ cells, macrophages, neutrophils and natural killers. On the other hand, trans pathway will act on endothelial cells, giving rise to VEGF, MCP-1 (monocyte chemoattractant protein -1), IL6, IL8 and reduced $\mathrm{E}$-cadherin(21). Most of the hosts are able to control the infection and minimize lung damage through the mechanism previously described. Nevertheless, some patients undergo an uncontrolled production of cytokines that exacerbates not only lung damage but also fosters multiorgan injury, and coagulation cascade activation(22).

The mechanism behind the production of a cytokine storm is not fully understood, but a delayed type 1 IFN (interferon) response may contribute. SARS-COV-1, and possibly SARS-COV-2, contain proteins that interrupt an early type 1 IFN response, facilitating viral replication ${ }^{(23)}$. Thereafter, once type 1 IFN reaction finally activates, it promotes a disproportionate infiltration of immune cells to the parenchyma, hence, activating pro inflammatory cytokines such as IL2, IL7, G-CSF, PI10, MIP1, and TNF alpha, and causing the most severe cases of infection ${ }^{(20)}$. Undoubtedly, a hyperproduction of cytokines and a proinflammatory context induced by SARS-CoV-2 links to the severity of the disease, clinically evidenced by an acute respiratory distress syndrome in which pulmonary microvascular and alveolar epithelial cells are damaged, as part of the pathophysiology of CAC(24). 


\section{Procoagulating factors in vascular endothelium}

Cytokine expression stimulates endothelial activation and thrombosis, creating a connection between inflammatory and prothrombotic pathways. One explanation of this endothelial affectation could be that SARS-CoV-2 induces an elevated angiotensin release ${ }^{(25)}$. Therefore, angiotensin upregulates the expression of ROS and dysregulates the activation of antioxidant and vasodilatory pathways such as NOX2 and eNOS causing endothelial damage. Moreover, ARDS created by a cytokine storm, promotes pulmonary vasoconstriction and creates an hypoxic environment which potentiates the cell damage(23).

The second event is the prothrombotic effect, that is explained by both, the activation of the intrinsic and extrinsic pathway within an immunity-inflammatory context(26). On one hand, the overexpression of tissue factor by the injured endothelial cells and the activated macrophages, leads to the initiation of the extrinsic pathway. And at the other hand, the intrinsic pathway is initiated by the activation of factor XII as consequence of intravascular DAMPS release mediated by NETOSIS(27) The third mechanism associated is increased secretion of Von Willebrand Factor due to the endothelial damage. Hence, the excessive amount produces a deficiency with ADAMTS13 in response to viral systemic inflammation ${ }^{(28)}$. Finally the excess of VWF recruits platelets, which when activated produce neutrophilsplatelets complexes that causes micro-thrombogenesis within microvasculature ${ }^{(29)}$. Another important event is that PROS 1 is depleted by the formation of the clot. PROSI serves as one of the two activation ligands for the TAM family of the RTKs receptor, an immunosuppressive activator. Thus, deficiencies in TAM receptor and PROS1 are associated with chronic immune hyperactivation which leads to endothelial damage ${ }^{(30)}$

\section{Hypercoagulability (Thrombosis of microcirculation and circulation, a systemic effect)}

Once the cytokine storm is established following SARS-CoV2 infection and endothelial injury has occurred, an extensive interplay is present among endothelial cells, monocytes/ macrophages, platelets, neutrophils, and proteins of the coagulation cascade and complement pathways. The interaction among all the above-mentioned components lead to a hypercoagulable state with increased levels of procoagulant and decrease in anticoagulant factors, and hypofibrinolysis(23). The latter is the result of an imbalance state between TPA/UPA and an excess of PAI-1, a finding that may explain the fibrin deposits in the alveoli and perialveolar capillary microthrombosis found in some ARDS patients ${ }^{(31)}$.

As the hyperinflammation state expands, the immunothrombosis process progresses and multiorganic dysfunction sets up soon. This hypercoagulable state may be amplified by many factors: hypoxemia because of ARDS (it induces HIF gene factors expression which boost hypercoagulability through augmentation of blood viscosity, activation of platelets and coagulation factors, promoting further imbalance between TPA/UPA and PAI-1, and inhibition of protein $S^{(32)}$, hyperthermia (it activates platelets) and/or hypovolemia due to negative fluids balance secondary to ARDS protocols treatment ${ }^{(33)}$. Although not completely characterized yet, many studies have mentioned the importance of antiphospholipid antibodies (such as, anticardiolipin IgA, anti- $\beta 2$ glycoprotein and lupus anticoagulant) in the hypercoagulable state found in some patients ${ }^{(34)}$.

Additionally, an aberration of the RAA system could also explain many of the findings seen in the immuno-thrombosis process. As reviewed earlier, SARS-COV2 targets ACE2, thus preventing AngII to be metabolized into Ang 1-7; Ang-II induces expression of TF and PAI-1, therefore, it contributes to the imbalance state between TPA and PAI- (23). $^{(23)}$ Another remarkable finding that in part explains why COVID-19 is more severe in obese patients, is because Angll also stimulates PAl-1 release from adipocytes via ATl receptors(35). Furthermore, ACE protein metabolizes bradykinin into inactive metabolites, consequently, preventing it from exerting its vasodilation properties and release of tPA, thus promoting hypofibrinolysis(36).

\section{Clinical Manifestations}

\section{The initial clinical manifestations}

The spectrum of thromboembolic manifestations of patients with COVID-19 can be broad and appears to have variations among different individuals(37). The hypercoagulable state that might appear in individuals with COVID-19 is characterized by venous and arterial thromboembolism, although venous thromboembolism appears to be more common. The most frequent clinical manifestations are: deep venous thrombosis (DVT), pulmonary embolism (PE), ischemic and hemorrhagic stroke, myocardial infarction, and arterial embolism(38). Symptoms consistent with DVT, such as asymmetric pain, swelling of the lower extremities, local swelling of the lateral limbs after catheterization of the central vein, hypotension or any unilateral leg symptom, or with PE like hypoxemia should be taken in consideration for prevention and treatment of COVID-associated coagulopathy(39). Severe COVID-19 patients should be screened for DVT based on their inflammatory markers and clinical features. For the outpatient, the presence of any of these symptoms should be highly suspicious for DVT via telehealth, and if not, close monitoring should be executed(14).

\section{Stratification of coagulation state in patients}

Patients with COVID-19 infection have worse prognosis if they develop coagulopathy during the course of the disease ${ }^{(40)}$. Older age, the presence of certain comorbidities or underlying conditions, and some image findings related to coagulation abnormalities are also associated with mortality in COVID-19 infection ${ }^{(41)}$. 


\begin{tabular}{|c|c|}
\hline Age & $\begin{array}{l}\text { Older age is related to vascular and } \\
\text { homeostatic changes that increase the } \\
\text { risk of thrombotic complications. }\end{array}$ \\
\hline $\begin{array}{l}\text { Underlying } \\
\text { conditions }\end{array}$ & $\begin{array}{l}\text { Severe pneumonia, admission to Inten- } \\
\text { sive Care Unit (ICU), Coronary Care Unit } \\
\text { (CCU) setting, Virchow triad }\end{array}$ \\
\hline Comorbidities & $\begin{array}{l}\text { Diabetes, Coronary Artery Disease, } \\
\text { Obesity, Hypertension, Venous trom- } \\
\text { boemolism (VTE) and Cancer are } \\
\text { related to endothelial damage and } \\
\text { alterations in the coagulation cascade. }\end{array}$ \\
\hline $\begin{array}{l}\text { Other clinical } \\
\text { features }\end{array}$ & $\begin{array}{l}\text { Unexplained sudden deterioration of } \\
\text { pulmonary status, acute lower erythe- } \\
\text { ma or swelling }\end{array}$ \\
\hline $\begin{array}{l}\text { Coagulation } \\
\text { markers }\end{array}$ & $\begin{array}{l}\text { D-dimer } \\
\text { Prothrombin time } \\
\text { Activated partial thromboplastin time } \\
\text { Platelet count } \\
\text { Fibrinogen }\end{array}$ \\
\hline Image findings & $\begin{array}{l}\text { Echocardiography: Right ventricular } \\
\text { strain associated with Pulmonary Em- } \\
\text { bolism } \\
\text { Ultrasound: upper and lower limbs: eva- } \\
\text { luate Deep Venous Thrombosis (DVT) }\end{array}$ \\
\hline
\end{tabular}

Coagulation markers, especially D dimer, are useful tools for understanding the nature of the coagulopathy and to classify it according the results, as well as other factors that might be considered when evaluation COVID-associated coagulopathy ${ }^{(42)}$ (Table 1). The three stages of COVID-19 Associated Hemostatic Abnormalities (CAHA), proposed by Thachil and collaborators, allow clinicians to categorize affected patients in 3 stages that follow the pathophysiology of the process, based in clinical aspect, laboratory and image results, so as to establish a possible treatment for their condition ${ }^{(43)}$. Table 2 was created to summarize the 3 proposed stages. Evaluation of a patient with COVID-19 infection must be done carefully in order to aid early recognition, prognosis determination and decision-making about the management of the coagulopathy.

\section{Diagnosis and Evaluation}

\section{Laboratory exams}

A significant proportion of COVID-19 patients develop important coagulation abnormalities, which may result in venous and arterial thromboembolic complications ${ }^{(44)}$ and increased mortality rates ${ }^{(45)}$. Findings in COVID-19-associated coagulopathy, CAC, may resemble other coagulopathies associated with severe infection, such as sepsis induced coagulopathy (SIC), disseminated intravascular coagulation (DIC), hemophagocytic syndrome (HPS)/hemophagocytic

Table 2. Stages of COVID-19 Associated Hemostatic Abnormalities (CAHA) *

\section{Stages Clinical aspect}

I Non-severe symptoms Outpatient or Hospital inpatient.

II Severe symptoms Critical care support required

III Clinically worsening patient. Higher-level critical care support (EMO) Overt DVT Multi-organ failure Ischemia (gut, limbs, coronary or cerebral vasculature)

\section{Laboratory markers}

Elevated D-dimer (2 to 3 fold above normal) Normal PT

Normal PTT

Normal or elevated platelet count Normal or elevated fibrinogen

Elevated D-dimer ( 3 to 6 fold above normal) Mildly reduced platelet count (100 - 150 x 109)

Minor prolonged PT

Elevated D-dimer ( $>6$ fold above normal) Significant thrombocytopenia Marked prolonged PT and PTT Decreased fibrinogen

\section{Image studies}

Usually none or missed findings on CT nor US for pulmonary micro-thrombi or DVT respectively

Filling defects on CT (pulmonary thrombi or emboli) Asymptomatic DVT

Extensive pulmonary thrombi that compromises both lungs. Systemic thrombosis.

PT: Prothrombin time, PTT: Partial thromboplastin time, CT: Computerized tomography, US: Ultrasound, DVT: Deep Vein Thrombosis, EMO: Extracorporeal membrane oxygenation

* This table was adapted by the authors of this paper, based on the one created by Thachil and collaborators, 2020 (43) 
lymphohistiocytosis (HLH), antiphospholipid syndrome (APS), and thrombotic microangiopathy (TMA); however, CAC should be considered as a separate entity as it does not entirely fit in other coagulopathies(18). The most common pattern found in patients with CAC is an increased D-dimer value, relative thrombocytopenia and a slightly prolonged prothrombin time $(\mathrm{PT})^{(45)}$. D-dimer values tend to be significantly higher in patients with CAC, and thrombocytopenia is usually less evident than in other coagulopathies, such as DIC ${ }^{(44)}$. It is important to consider that consumptive coagulopathy, which is a classical feature of $\mathrm{DIC}$ and SIC, is not present in early-stage CAC(12). Importantly, prolongation of PT, degree of thrombocytopenia and D-dimer elevation have been associated with a higher mortality in patients with COVID-19(46). Thus, a coagulation profile should be obtained in hospitalized patients with COVID-19, including PT, activated partial thromboplastin time (aPTT), D-dimer, platelet count and fibrinogen, in order to identify CAC features and establish the prognosis(47)

As mentioned before, a complex inflammation cascade is triggered in response to SARS-CoV-2 infection. This innate response may activate the coagulation pathway, in a process known as thrombo-inflammation or immune-thrombosis. Therefore, the abnormalities in the coagulation biomarkers are most likely a result of the intense inflammatory response, rather than due to specific pro-coagulant properties of the virus ${ }^{(47)}$. In severe cases of COVID-19, the hyperactivation of the inflammatory pathway can lead to an overproduction of proinflammatory cytokines between day 7 to 14 of the disease(48), known as a cytokine storm, which may cause the symptoms of the disease and eventually death(49). The inflammatory cytokines and biomarkers that can potentially determine high risk patients include interleukin IL-2, IL-6, IL-7, tumor necrosis factor- $\alpha$ (TNF- $\alpha$ ), macrophage inflammatory protein 1- $\alpha$ (MIP1- $\alpha$ ), granulocytecolony stimulating factor (G-CSF), lactate dehydrogenase (LDH), C-reactive protein (CRP), ferritin, and D-dimer ${ }^{(50)}$.

The cytokines that are more likely to predict the severity of the disease are IL-6 and IL-10(51). IL6 is a multifunctional cytokine and a strong proinflammatory effect, also is a key role in the acute response and it is used as an early biomarker in sepsis and lung injury and predictive factors of lung disease, organ dysfunctions and mechanical ventilation ${ }^{(52)}$. IL-10 may be related to compensatory anti-inflammatory response in the severe forms of the disease, and the reason of secondary infections in non survivors ${ }^{(53)}$. The CPR, C-reactive protein, is induced by IL-6 in the liver as a sensitive biomarker of inflammation, infection or tissue damage ${ }^{(54)}$. In COVID-19 patients, elevated levels of CPR in early stage could reflect lung lesions and disease severity ${ }^{(55)}$. On the other hand, procalcitonin and serum ferritin have shown a poor clinical prognosis, and a higher serum ferritin was associated with acute respiratory distress syndrome (ARDS). Elevated procalcitonin and lactate dehydrogenase can suggest a secondary bacterial infection complicating the clinical course of COVID-19 in severe cases $^{(48)}$.

According to the $\mathrm{NIH}$, in non-hospitalized patients with COVID-19, there are currently no data to support the routine measurement of coagulation markers (e.g., D-dimers, PT, aPTT, platelet count, fibrinogen). However, in hospitalized patients with COVID-19, hematologic, coagulation parameters and inflammatory biomarkers are commonly measured, although there are currently insufficient data to recommend for or against using this data to guide management decisions( ${ }^{(56)}$.

\section{Imaging and echography}

Patients with severe COVID-19 infection have an increased risk of developing venous thromboembolism (VTE) and pulmonary embolism (PE) due to an hypercoagulable state, endothelial injury and immobilization(47). Considering this, a high-level of suspicion for thromboembolism is warranted, especially if there is any sign of respiratory deterioration in criticallyill patients ${ }^{(39)}$. Deep venous thrombosis (DVT) can be detected through bilateral compression ultrasonography (CUS) of the legs, while PE can be detected through echocardiography or point-of-care ultrasonography (POCUS) and computed tomography with pulmonary angiography(57). Table 3 (based in Manna et. al $2020{ }^{(58)}$ and Torres et al. 2020(59)), summarizes general findings of complications for thromboembolism and pulmonary embolism found in different imaging device, which could be helpful for a quicker diagnosis. First, for ultrasonography, CHEST guidelines suggest a routine ultrasound screening to detect DVT only in critically ill (not in asymptomatic) patients or situations like: suspected pulmonary embolism (PE), unexplained ventricular dysfunction and a refractory hypoxemia( ${ }^{(60)}$. The utility of ultrasound is based on its advantages like availability, rapidity, and safety especially considering that $50-70 \%$ patients with PE have an underlying $D V T^{(61)}$. Second, echocardiography is not useful as a screening tool due to its low sensitivity and high rate of false-positive findings in diagnosis of PE. Furthermore, it lacks the ability to visualize the pulmonary vessels ${ }^{(58)}$. Third, initial routine imaging like chest $X$-ray do not provide adequate information to diagnose PE, however, indirect signs could be helpful (Table 3). Finally, computed tomographic angiography (CTA) is a powerful tool to stratify risk and detect PE in hemodynamically stable patients ${ }^{(58)}$. Its limitations include its low availability, higher chances of transmission, difficulty venous access, and the use of contrast in renal impairment or allergy.

\section{Management}

When evaluating if there is high risk of thromboembolism, physicians must consider certain parameters that could guide the clinical suspicion such as labored breathing, respiratory rate $>24 /$ min, decreased SpO2 (<90\%), elevated C-reactive protein, rising $\mathrm{D}$-dimers levels and evaluating fibrinogen levels(62).

\section{Outpatient management}

Despite the increased risk of coagulopathy in COVID-19 patients, the NIH gives a strong recommendation, based on expert opinion, that for non-hospitalized patients with COVID-19, anticoagulants and antiplatelet therapy 
should not be initiated for the prevention of VTE or arterial thrombosis. The only exception is given for patients who have other indications for the therapy or who are participating in a clinical tria|(56).

Table 3. General findings of complications for thromboembolism and pulmonary embolism found in different imaging device*

\section{Imaging device Ultrasonography}

Echocardiography
Chest X-ray

\section{Findings}

Visualization of the thrombus Absence of color flow

Non-comprensible venous segment Increased venous diameter

Right heart thrombus

McConnel sign+ paradoxical interventricular septal movements

\section{Computed tomogra- phic angiography}

complete arterial occlusion partial filling defects of the contrast

peripheral partial filling defects forming acute angles with arterial walls

Westermark sign ${ }^{\odot}$

Hampton's hump ${ }^{x}$

Fleischner's sign ${ }^{\Delta}$

Palla's sign ${ }^{\Sigma}$

+ akinesis of the free wall of the right ventricle and hypercontractility of the apical wall

- focal oligemia

x pleural-based wedge shape consolidation because pulmonary infarction

$\triangle$ enlargement pulmonary artery

$\Sigma$ vascular prominence before arterial occlusion

* This table was originally created by the authors of this paper.

\section{Inpatient management}

All hospitalized patients with COVID-19 should receive prophylactic therapy for venous thromboembolism (VTE) (56). Parenteral anticoagulation is suggested with Low Molecular Weight Heparin (LMWH), over Unfractionated Heparin (UFH) and oral anticoagulants, unless there are clear contraindications (e.g., active bleeding, serious bleeding in the prior 24-48h, platelet count less than $25,000 \ldots)^{(63)}$. In cases of renal replacement therapy or creatinine clearance $(\mathrm{CrCl})$ less than $15 \mathrm{~mL} / \mathrm{min}$, unfractioned heparin (UFH) is recommended ${ }^{(64)}$. In patients with history of heparin-induced thrombocytopenia, fondaparinux is the drug of choice ${ }^{(65)}$.

When feasible, it is reasonable to use strategies to minimize infection risk by medical personal and patient contact (e.g., use of daily LMWH rather than thrice-daily UFH injections) (66). This treatment should be continued until symptoms and infection are resolved. The decision to continue postdischarge thromboprophylaxis should consider the individual patient's risk factors (VTE, recent surgery, trauma or immobilization), bleeding risks, and feasibility. ${ }^{(56)}$

For those patients with COVID who are on therapeutic anticoagulation for other indications such as atrial fibrillation, mechanical cardiac valves, or long term secondary VTE prevention, it is recommended to receive full dose or a dose equivalent to their current doses ${ }^{(56)}$. LMWH or UFH are preferred over direct oral anticoagulants because their shorter half-lives, ability to be administered intravenously or subcutaneously, and fewer drug-drug interactions ${ }^{(47)}$. In patients who do not have any therapeutic anticoagulation recommended before admission but develop definitive VTE or highly suspected VTE where standard confirmatory testing cannot be performed, myocardial infarction, clotting of vascular devices, despite prophylactic anticoagulation, a full dose anticoagulation therapy should be given unless there are contraindications for anticoagulation ${ }^{(56)}$. Table 4 summarizes different anticoagulation regimens based on type of anticoagulant and different medical conditions. Patients with confirmed venous thromboembolism who are discharged from hospital, should continue anticoagulation for a minimum time of three months ${ }^{(67)}$.

\section{Intensive Care Unit management}

In critically ill patients admitted to ICU the thromboprophylaxis should be intermediate doses of LMWH 40-60 mg daily drip to parenteral protocol to target an active partial thromboplastin time (aPTT) between 60-85s which are associated with better outcomes and prognosis ${ }^{(69)}$. It is important to consider BMI for adjusting doses. In cases of high hemorrhagic risk, thromboprophylaxis will preferably be performed with mechanical methods (intermittent pneumatic compression). In these circumstances, it is suggested to value the performance of viscoelastic tests as a complement to the monitoring of hemostasis. After the discharge of the patient in this condition, thromboprophylaxis should be continued for up to 14-30 days, where LMWH or OAC can be used(69). Full dose anticoagulation for $\mathrm{UCl}$ patients should be administered under the same recommendations as for non-UCl patients. Patients who suffered VTE/DVT should continue anticoagulation therapy for at least 3 months ${ }^{(69)}$.

\section{New proposed approaches}

A large NIH multiplatform, adaptive-design trial that incorporates 3 global studies/networks (REMAP-CAP, ATTACC and ACTIV-4A) was established to compared the effectiveness of therapeutic dose anticoagulation and prophylactic dose anticoagulation in reducing the need for organ support over 21 days in moderately ill or critically ill adults hospitalized for COVID-19 ${ }^{(8)}$. The results of the interim analysis, released at the end of January 2021, suggest that full dose anticoagulation might be superior to standard care prophylactic dose anticoagulation (OR 1.5; 1.1 
Table 4. Anticoagulation doses in COVID-19 patients, as recommended by Massachusetts General Hospital (68)*

$\begin{array}{ll} & \text { Enoxaparine } \\ \begin{array}{l}\text { Standard } \\ \text { dose }\end{array} & 1 \mathrm{mg} / \mathrm{kg} \mathrm{SQ} \text { q } 12 \mathrm{~h}\end{array}$

Renal $\quad \mathrm{CrCl} 15-29 \mathrm{ml} / \mathrm{min}: 1 \quad$ No dose adjustment Adjustment $\mathrm{mg} / \mathrm{kg} \mathrm{SQ}$ q $24 \mathrm{~h}$

$\mathrm{CrCl} \neg<15 \mathrm{ml} / \mathrm{min}$ : consult with pharmacy and local protocols

Hepatic No dose adjustment Adjustment
Obesity
$\mathrm{CrCl}>30 \mathrm{ml} / \mathrm{min}$ :
BMI>40 kg/
$0.75 \mathrm{mg} / \mathrm{kg}$ q $12 \mathrm{~h}$
m2
$\mathrm{CrCl}<30 \mathrm{ml} / \mathrm{min}$;
$0.75 \mathrm{mg} / \mathrm{kg}$ q $24 \mathrm{~h}$
$>150 \mathrm{~kg}$ : Use is not
recommended

Acute coronary syndrome (ACS): 60 unit/

$\mathrm{kg}$ bolus + 12 units/kg/ hr infusion

\author{
Unfractionated Hepa- \\ rin (UFH) \\ Venous thromboem- \\ bolism (VTE) or Atrial \\ fibrillation (Afib): 80 \\ units/kg bolus +18 \\ unitis/kg/hr infusion
}

$\mathrm{CrCl}<30 \mathrm{ml} /$ min Use is not recommended

Argatroban
$0.25 \mathrm{mcg} / \mathrm{kg} /$
min (usual star-
ting dose)

Bivalirudin

<50kg: $5 \mathrm{mg} \mathrm{SQ}$ q $24 \mathrm{~h}$

50-100 kg: 7.5

SQ mg q $24 \mathrm{~h}$

$>100 \mathrm{~kg} 10 \mathrm{SQ}$

$\mathrm{mg}$ q $24 \mathrm{~h}$

No dose adjustment

Consult with Pharma- $\quad>100 \mathrm{~kg}: 10 \mathrm{mg}$ cy and local protocols q 24h

Limited Data
No dose adjustment

\section{Moderate \\ (Child-Pugh B) : \\ $0.5 \mathrm{mcg} / \mathrm{kg} / \mathrm{min}$}

\section{$0,15 \mathrm{mg} / \mathrm{kg} / \mathrm{hr}$}

$\mathrm{CrCl} 30-60 \mathrm{~mL} /$ min: $0.05 \mathrm{mg} /$ $\mathrm{kg} / \mathrm{hr}$

$\mathrm{CrCl}<30 \mathrm{ml} / \mathrm{min}$ : $0,025 \mathrm{mg} / \mathrm{kg} / \mathrm{hr}$

Severe

(Child-Pugh C): Use bivalirudin

Limited Data

Limited Data

Consult local with Pharmacy and local protocols

No dose adjustment

Consult local with Pharmacy and local protocols

* This table was adapted by the authors of this paper, based on the one created by Massachusetts General Hospital, 2020 (68)

- 2.2) in lowering the need for organ support and mortality in moderately ill hospitalized COVID-19 patients, understood as those patients who required in-hospital management different to ICU. This same interim analysis suggests the futility of full dose anticoagulation in reducing the need for organ support and mortality, compared with usual care prophylactic dose anticoagulation in patients managed at the ICU, which are considered to be severe cases ${ }^{(14)}$. Peer review analysis is still pending. However, we recommend considering this new data when deciding prophylaxis treatment of COVID-19 associated coagulopathy in patients with moderate to severe disease.

\section{Treatment of bleeding}

Bleeding does not seem to be a major manifestation of patients with COVID-19(70). However, patients may have bleeding for other reasons, like trauma and/or anticoagulation therapy. The approach to bleeding is similar to individuals without COVID-19 and involves anticoagulant reversal and/or discontinuation, transfusions for thrombocytopenia or hypofibrinogenemia, or specific therapies such as factor replacement(71).

\section{Role of antiplatelet therapy}

The role of antiplatelet agents is currently under study. Antiplatelet therapy administration is not recommended outside of standard indications ${ }^{(71)}$. It is reasonable to continue antiplatelet therapy if the individual is already receiving it for another justified indication ${ }^{(72)}$.

\section{Conclusion}

The link between COVID-19 and a hypercoagulable state has been well documented in the previous months, and it is associated with acute inflammatory changes and particular laboratory findings that make it different from those of acute disseminated intravascular coagulation (DIC). COVIDassociated coagulopathy, CAC, is especially prevalent in patients with moderate to severe 
disease, and certain factor are related with an increased risk for developing it, like being managed at the ICU, older age and comorbidities (see Table 1). Among laboratory findings, fibrinogen and D-dimer tend to be increased, with only modest prolongation of both the prothrombin time (PT) and the activated partial thromboplastin time (aPTT). Regarding platelets, mild thrombocytosis or thrombocytopenia are typically seen. The pathogenesis of these abnormalities is not fully understood yet, although the host inflammatory response to the infection appears to be a crucial element in the development of CAC.

Generally, all patients admitted to the hospital with a diagnosis of COVID-19 should have a laboratory test done, which must include baseline complete blood count, with platelet count, PT, aPTT, fibrinogen, and D-dimer. People being managed in the outpatient setting do not require coagulation testing, unless there is another justified indication for it. Imaging studies might be appropriate when there is a high-level of suspicion for VTE, which includes deep venous thrombosis and pulmonary thromboembolism (see Table 3). A scale based on the stages of CAC can be used to better understand and classify patients with a hypercoagulable state related to COVID-19 (see Table 2).

All inpatients must receive thromboprophylaxis unless there is a clear contraindication, while outpatients should not receive it unless clearly justified by another reason. New preliminary data suggests that full dose anticoagulation might be superior to standard care prophylactic dose anticoagulation in lowering the need for organ support and mortality in moderately ill hospitalized COVID-19 patients; this same new data points out the futility of full dose anticoagulation in reducing the need for organ support and mortality in patients managed at the ICU, compared with usual care prophylactic dose anticoagulation. Peer review is still needed before making this recommendation widely available.

Low molecular weight heparin (LMWH) is generally preferred to unfractionated heparin or oral anticoagulants, but unfractionated heparin can be used if LMWH is not available or if there is severe renal impairment (see Table 4). Protocols may vary by institution and country. Full therapeutic dose of anticoagulation is appropriate when deep vein thrombosis (DVT) or pulmonary embolism (PE) are confirmed or highly suspected. This therapy must be continued for at least three months. For patients who did not have an episode of venous thrombosis, thromboprophylaxis after discharge from the hospital is not recommended. Bleeding is much less common than thrombosis, and when it occurs, the management should follow the recommendations given for patients who do not have COVID-19. There is no clear role for antiplatelet therapy.

\section{Referencias}

1. Sun J, He W-T, Wang L, Lai $A$, Ji X, Zhai $X$, et al. COVID-19: Epidemiology, Evolution, and CrossDisciplinary Perspectives. Trends Mol Med. 2020;26(5):483-95.

2. Hu B, GUO H, Zhou P, Shi Z. Characteristics of SARSCoV-2 and COVID-19 | Nature Reviews Microbiology. 2020 October 06.

3. Chen N, Zhou M, Dong X, Qu J, Gong F, Han Y, et al. Epidemiological and clinical characteristics of
99 cases of 2019 novel coronavirus pneumonia in Wuhan, China: a descriptive study. The Lancet. 2020 Feb 15;395(10223):507-13.

4. Cucinotta D, Vanelli M. WHO Declares COVID-19 a Pandemic. Acta Bio Medica Atenei Parm. 2020:91(1):157-60.

5. Jin Y, Yang H, Ji W, Wu W, Chen S, Zhang W, et al. Virology, Epidemiology, Pathogenesis, and Contro of COVID-19. Viruses. 2020 Apr; 12(4):372.

6. Temgoua M, Angong F, Nkeck J, Kenfack G Essouma M, Noutakdie J. Coronavirus Disease 2019 (COVID-19) as a Multi-Systemic Disease and its Impact in Low- and Middle-Income Countries (LMICS) [Internet]. [cited 2020 Nov 29]. Available from: https://www.researchgate. net/publication/343091346_Coronavirus_Disease_2019_COVID-19 as_a_Multi-Systemic_Disease_and_its_Impact_in_Low-_and_Middle-Income Countries_LMICS

7. Hopkins C, Surda P, Kumar B. Presentation of New Onset Anosmia During the COVID-19 Pandemic. Rhinology. 2020 Apr 1 1:58.

8. Clinical Presentation [Internet]. COVID-19 Treatment Guidelines. [cited 2020 Nov 29]. Available from: https://www.covidl9treatmentguidelable from: https://www.covid/ptreatmentguide
lines.nih.gov/overview/clinical-presentation/

9. Becker RC. COVID-19 update: Covid-19-associated coagulopathy. J Thromb Thrombolysis. 2020 May $15 ; 1-14$

10. Martín $\square$ Rojas RM, Pérez $\square$ Rus G, Delgado $\square$ Pinos $\mathrm{VE}$, Domingo $\square$ González A, Regalado $\square$ Artamend
I, Alba $\square$ Urdiales N, et al. COVID-19 coagulopathy: An in-depth analysis of the coagulation system Eur J Haematol. 2020;105(6):741-50.

11. Brady L. Stein MD. COVID-19 Coagulopathy: Excess Thrombosis. NEJM J Watch [Internet]. 2020 Aug 13 [cited 2020 Nov 29];2020. Available from: https://www.jwatch.org/NA52177/2020/08/13/ covid-19-coagulopathy-excess-thrombosis

12. Iba T, Levy JH, Levi M, Thachil J. Coagulopathy in COVID-19. J Thromb Haemost. 2020;18(9):2103-9.

13. Ackermann M, Verleden SE, Kuehnel M, Haverich A, Welte $T$, Laenger $F$, et al. Pulmonary Vascula Endothelialitis, Thrombosis, and Angiogenesis in Covid-19. N Engl J Med. 2020 09;383(2):120-8.

14. Connors J, Levy J. COVID-19 and its implications for thrombosis and anticoagulation | Blood American Society of Hematology [Internet]. [CiAmerican Society of Hematology [Internet]. [Ci-
ted 2020 Dec 9]. Available from: https://ashpublications.org/blood/article/135/23/2033/454646/ COVID-19-and-its-implications-for-thrombosis-and

15. Helms J, Tacquard C, Severac F, Leonard-Lorant I, Ohana $M$, Delabranche $X$, et al. High risk of throm bosis in patients with severe SARS-CoV-2 infection: a multicenter prospective cohort study. Intensive Care Med. 2020;46(6):1089-98.

16. Debuc B, Smdja D. Is COVID-19 a New Hematologic Disease? | SpringerLink [Internet]. [cited 2020 Dec 9]. Available from: https://link.springer.com/ article/10.1007/s12015-020-09987-4

17. Teuwen L, Geldhof V, Pasut A, Carmeliet P. COVID-19: the vasculature unleashed | Nature Reviews Immunology [Internet]. [cited 2020 Dec 9]. Available from: https://www.nature.com/articles/ s41577-020-0343-0

18. Iba T, Levy JH, Connors JM, Warkentin TE, Thachi J, Levi M. The unique characteristics of COVID-19 coagulopathy. Crit Care. 2020 Jun 18:24(1):360.

19. Guo H, Sheng Y, Li W, Li F, Xie Z, Li J, et al. CoaCOVID-19-Infected Patients. Front Med [Inter- net]. 2020 Oct 23 [cited 2020 Dec 9];7. Available from: https://www.ncbi.nlm.nih.gov/pmc/articles/ PMC7645068/

20. Moore JB, june $\mathrm{CH}$. Cytokine release syndrome in severe COVID-19. Science. 2020 May 01; 368:473 474.

21. Tay MZ, Poh CM, Rénia L, MacAry PA, Ng LFP. The trinity of COVID-19: immunity, inflammation and intervention. Nat Rev Immunol. 2020;20(6):363-74.

22. Jose RJ, Manuel A. COVID-19 cytokine storm: the interplay between inflammation and coagulation. Lancet Respir Med. 2020;8(6):e46-7.

23. Henry BM, Vikse J, Benoit S, Favaloro EJ, Lippi G Hyperinflammation and derangement of renin-angiotensin-aldosterone system in COVID-19: A novel hypothesis for clinically suspected hypercoagulopathy and microvascular immunothrombosis. Clin pathy and microvascular immunothrombosis. Clin
Chim Acta Int J Clin Chem. 2020 Aug;507:167-73.

24. Song P, Li W, Xie J, Hou Y, You C. Cytokine storm induced by SARS-CoV-2. Clin Chim Acta Int J Clin Chem. 2020 Oct:509:280-7.

25. Henry BM, Santos de Oliveira MH, Benoit S, Pleban M, Lippi G. Hematologic, biochemical and immu ne biomarker abnormalities associated with severe illness and mortality in coronavirus disease 2019 (COVID-19): a meta-analysis - PubMed [Internet] [cited 2020 Dec 9]. Available from: https://pubmed.ncbi.nlm.nih.gov/32286245/

26. Cao W, Li T. COVID-19: towards understanding of pathogenesis. Cell Res. 2020 May;30(5):367-9.

27. Giannis D, Ziogas I, Gianni P. Coagulation disorders in coronavirus infected patients: COVID-19, SARSCOV-1, MERS-COV and lessons from the past. J Clin Virol. 2020 Apr 1;127:104362.

28. Varatharajah N, Rajah S. Microthrombotic Complications of COVID-19 Are Likely Due to Embolism of Circulating Endothelial Derived Ultralarge Von Willebrand Factor (eULVWF) Decorated-Platelet Strings [Internet]. [cited 2020 Dec 28]. Available from: https://www.ncbi.nlm.nih.gov/pmc/articles/ from: https://Ww
PMC7241602/ 
29. Joly BS, Siguret $V$, Veyradier A. Understanding pathophysiology of hemostasis disorders in critically ill patients with COVID-19 | SpringerLink [Internet]. [cited 2020 Dec 28]. Available from: https://link.springer.com/article/10.1007/s00134020-06088-1

30. Lemke G, Silverman GJ. Blood clots and TAM receptor signalling in COVID-19 pathogenesis. Nat Rev Immunol. 2020 Jul;20(7):395-6.

31. Kwaan HC. Coronavirus Disease 2019: The Role of the Fibrinolytic System from Transmission to Organ Injury and Sequelae. Semin Thromb Hemost. 2020 Oct 1;46(7):841-4.

32. Schulman S. Coronavirus Disease 2019, Prothrombotic Factors, and Venous Thromboembolism. Semin Thromb Hemost. 2020 May; 46(7).

33. Meyer MAS, Ostrowski SR, Overgaard A, Ganio MS, Secher NH, Crandall CG, et al. Hypercoagulability in response to elevated body temperature and central hypovolemia. J Surg Res. 2013 Dec; 185(2):e93-100.

34. Zhang $Y$, Xiao $M$, Zhang S, Xia P, Cao W, Jiang W, et al. Coagulopathy and Antiphospholipid Antibodies in Patients with Covid-19 | NEJM [Internet]. [cited 2020 Dec 28]. Available from: https://www. nejm.org/doi/full/10.1056/NEJMc2007575

35. Skurk T, Lee YM, Hauner H. Angiotensin II and its metabolites stimulate PAI-1 protein release from human adipocytes in primary culture. Hypertens Dallas Tex 1979. 2001 May;37(5):1336-40.

36. Stoll D, Yokota R, Sanches Aragão D, Casarini DE. Both aldosterone and spironolactone can modu-
late the intracellular ACE/ANG II/ATI and ACE2/ late the intracellular ACE/ANG $I I / A T 1$ and ACE2/
ANG (1 $\square 7) / M A S$ receptor axes in human mesanANG (1,7)/MAS receptor axes in human mesan-
gial cells. Physiol Rep [Internet]. 2019 Jun 4 [cited gial cells. Physiol Rep [Internet]. 2019 Jun 4 [cited
2020 Dec 28]; $7(11)$. Available from: https://www. ncbi.nlm.nih.gov/pmc/articles/PMC6548847/

37. Singhania N, Bansal S, Nimmatoori DP, Ejaz AA, MCCullough PA, Singhania G. Current Overview on Hypercoagulability in COVID-19. Am J Cardiovasc Drugs. 2020 Aug 4; $1-11$.

38. Abou-Ismail MY, Diamond A, Kapoor S, Arafah Y, Nayak L. The hypercoagulable state in COVID-19: Incidence, pathophysiology, and management. Thromb Res. 2020 Oct 1;194:101-15.

39. Aryal MR, Gosain R, Donato A, Pathak R, Bhatt VR, Katel A, et al. Venous Thromboembolism in COVID-19: Towards an Ideal Approach to Thrombodiol Rep [Internet]. 2020 [cited 2020 Dec 28]:22(7). Available from: https://www.ncbi.nlm.nih.gov/ pmc/articles/PMC7288258/

40. Polimeni A, Leo I, Spaccarotella C, Mongiardo A Sorrentino S, Sabatino J, et al. Prognostic Impact of Coagulopathy in Patients with COVID-19: a Meta-analysis of 35 Studies and 6427 Patients [Internet]. In Review; 2020 May [cited 2020 Dec 28]. Available from: https://www.researchsquare. com/article/rs-31 142/v1

41. Izcovich A, Ragusa MA, Tortosa F, Marzio MAL, Agnoletti C, Bengolea A, et al. Prognostic factors for severity and mortality in patients infected with COVID-19: A systematic review. PLOS ONE. 2020 Nov 17:15(11):e0241955.

42. Miesbach W, Makris M. COVID-19: Coagulopathy, Risk of Thrombosis, and the Rationale for Anticoagulation. Clin Appl Thromb [Internet]. 2020 Jul 17 [cited 2020 Dec 28];26. Available from: https://www.ncbi.nlm.nih.gov/pmc/articles/ PMC7370334/

43. Thachil J, Cushman M, Srivastava A. A Proposal for Staging COVID 19 Coagulopathy. Res Pract Thromb Haemost [Internet]. 2020 May 11 [cited 2020 Dec 28]; Available from: https://www.ncbi. nlm.nih.gov/pmc/articles/PMC7272892/
44. Levi M, Thachil J, Iba T, Levy JH. Coagulation abnormalities and thrombosis in patients with $\mathrm{CO}-$ VID-19. Lancet Haematol. 2020 Jun 1;7(6):e438-40.

45. Tang N, Li D, Wang X, Sun Z. Abnormal coagulation parameters are associated with poor prognosis in patients with novel coronavirus pneumonia. Thromb Haemost JTH. 2020 Apr; 18(4):844-7.

46. Hadid T, Kafri Z, Al-Katib A. Coagulation and anticoagulation in COVID-19. Blood Rev [Internet]. 2020 Oct 8 [cited 2021 Jan 1]; Available from: https://www.ncbi.nlm.nih.gov/pmc/articles/ PMC75439321

47. Connors JM, Levy JH. COVID-19 and its implications for thrombosis and anticoagulation. Blood. tions for thrombosis and antic
2020 Jun 4;135(23):2033-40.

48. Terpos E, Ntanasis-Stathopoulos I, Elalamy I, Kastritis E, Sergentanis TN, Politou M, et al. Hematological findings and complications of COVID $\square 19$ - Terpos - 2020 - American Journal of Hematology - Wiley Online Library [Internet]. [cited 2021 Jan 1]. Available from: https://onlinelibrary.wiley.com/doi/ full/10.1002/ajh.25829

49. Zhong J, Tang J, Ye C, Dong L. The immunology of COVID-19: is immune modulation an option for treatment? - The Lancet Rheumatology [Internet]. [cited 2021 Jan 1]. Available from: https://www. thelancet.com/journals/lanrhe/article/PIIS26659913(20)30120-X/fulltext

50. Siddiqi HK, Mehra MR. COVID-19 illness in native and immunosuppressed states: A clinicaltherapeutic staging proposal. J Heart Lung Transplant Off Publ Int Soc Heart Transplant. 2020 May:39(5):405-7.

51. Han $H$, Ma Q, Li C, Liu R, Zhao L, Wang W, et al. Profiling serum cytokines in COVID-19 patients re-

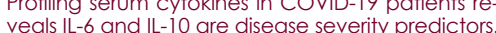
Emerg Microbes Infect. 2020 Dec;9(1):1 1 123-30.

52. Sun H, Guo P, Zhang L, Wang F. Serum Interleukin-6 Concentrations and the Severity of COVID-19 Pneumonia: A Retrospective Study at a Single Center in Bengbu City, Anhui Province, China in January and February 2020. Med Sci Monit Int Med J Exp Clin Res. 2020 Nov 11;26:e926941 1-e926941-6.

53. Henry BM, de Oliveira MHS, Benoit S, Plebani M Lippi G. Hematologic, biochemical and immune biomarker abnormalities associated with severe illness and mortality in coronavirus disease 2019 (COVID-19): a meta-analysis. Clin Chem Lab Med. 2020 Jun 25:58(7):1021-8.

54. Liu F, Li L, Xu M, Wu J, Luo D, Zhu Y, et al. Prognostic value of interleukin-6, C-reactive protein, and procalcitonin in patients with COVID-19. J Clin Virol. 2020 Jun; 127:104370.

55. Wang L. C-reactive protein levels in the early stage of COVID-19. Médecine Mal Infect. 2020 Jun $1 ; 50(4): 332-4$

56. Antithrombotic Therapy [Internet]. COVID-19 Treatment Guidelines. [cited 2021 Jan 1]. Available from: https://www.covid19treatmentguidelines.nih.gov/adjunctive-therapy/antithrombotic therapy/

57. Silva R, Gonçalves D, Cabral JP, Gomes B, Teixeira J, Mariz J. Triple POCUS: A New Approach to an Óld Problem. Eur J Case Rep Intern Med [Internet]. 2018 Sep 27 [cited 2021 Jan 1];5(9). Available from: https://www.ncbi.nlm.nih.gov/pmc/articles/ PMC6346822/

58. Manna S, Wruble J, Maron SZ, Toussie D, Voutsinas N, Finkelstein $M$, et al. COVID-19: A Multimodality Review of Radiologic Techniques, Clinical Utility, and Imaging Features. Radiol Cardiothorac Imaging. 2020 Jun 1;2(3):e200210.

59. Torres PPTES, Mançano AD, Zanetti G, Hochhegge B, Aurione ACV, Rabahi MF, et al. Multimodal in- direct imaging signs of pulmonary embolism. $\mathrm{Br} \mathrm{J}$ Radiol. 2020 Apr;93(1 108):20190635.

60. Moores LK, Tritschler T, Brosnahan S, Carrier M, Collen JF, Doerschug K, et al. Prevention, Diagnosis, and Treatment of VTE in Patients With Coronavirus Disease 2019. Chest. 2020 Sep; 158(3):1 1 43-63.

61. Parry AH, Wani AH. Pulmonary embolism in coronavirus disease-19 (COVID-19) and use of compression ultrasonography in its optimal managepression ultrasonography in its optimal
ment. Thromb Res. 2020 Aug; 192:36.

62. Becher Y, Goldman L, Schacham N, Gringauz I, Justo D. D-dimer and C-reactive Protein Blood l, Justo D. D-dimer and C-reactive Protein Blood bolism in Two COVID-19 Patients. Eur J Case Rep bolism in Two COVI-19 Patients. Eur J Case Rep Intern Med [Internet]. 2020 May 20 [cited 2021 Jan
1];7(6). Available from: https://www.ncbi.nlm.nih 1];7(6). Available from: https://Ww
gov/pmc/articles/PMC7279916/

63. Moores L, Tobias T, Brosnahan S, Le Gal G, Rali P Wells $P$, et al. Prevention, Diagnosis, and Treatment of VTE in Patients With Coronavirus Disease 2019 - CHEST [Internet]. [cited 2021 Jan 1]. Available
from: https://journal.chestnet.org/article/S00123692(20)31625-1/fulltext

64. Guideline for Anticoagulation and Prophylaxis Using Low Molecular Weight Heparin (LMWH) in Adult Inpatients. 2016;(4):15.

65. Atallah B, Mallah SI, AlMahmeed W. Anticoagulation in COVID-19. Eur Heart J - Cardiovasc Pharmacother. 2020 Jul 1;6(4):260-1.

66. Barnes G, Cuker A, Gluckman T, Piazza G, Siegel DM. Feature | Thrombosis and COVID-19: FAQs For Current Practice [Internet]. American ColleFor Current Practice Internet]. American Colle-
ge of Cardiology. [cited 2021 Jan 1]. Available ge of Cardiology. [cited 2021 Jan 1]. Available from: https://www.acc.org/latest-in-cardiology/ navirus-disease-2019-covid-19-faqs-for-currentpractice

67. Barnes $G D$, Burnett $A$, Allen A, Blumenstein $M$, Clark NP, Cuker A, et al. Thromboembolism and anticoagulant therapy during the COVID-19 pandemic: interim clinical guidance from the anticoagulation forum. J Thromb Thrombolysis. 2020 May 21;1-10.

68. Hematology Recommendations and Dosing Guidelines during COVID-19. Massachusetts General Hospital [Internet]. [cited 2021 Jan 4]. Available from: https://www.massgeneral.org/assets/MGH/ $\mathrm{pdf} / \mathrm{news} /$ coronavirus/guidance-from-mass-general-hematology.pdf

69. Spyropoulos A, Levy J, Ageno W, Connor JM, Hunt BJ, Iba T, et al. Scientific and Standardization Committee communication: Clinical guidance on the diagnosis, prevention, and treatment of venous thromboembolism in hospitalized patients with COVID 19. Journal of Thrombosis and Haemostasis [Internet]. [cited 2021 Jan 1]. Available from: tasis [Internet]. [Cited 2021 Jan 1]. Available from: https://o

70. Al-Samkari H, Karp Leaf RS, Dzik WH, Carlson JCT, Fogerty AE, Waheed A, et al. COVID-19 and coagulation: bleeding and thrombotic manifestations of SARS-COV-2 infection. Blood. $2020 \mathrm{Ju}$ 23;136(4):489-500.

71. Cuker A, Peyvandi F. Coronavirus disease 2019 (COVID-19): Hypercoagulability - UpToDate [Internet]. [cited 2021 Jan 1]. Available 19 -hypercoagulability? search = covid $\% 20$ anticoagulation \&source $=$ search result \&selec tedTitle=2 150\&usage_type=default \& display rank $=1$ \# H1099994068

72. Banik J, Mezera V, Köhler C, Schmidtmann M. Antiplatelet therapy in patients with Covid-19: A retrospective observational study. Thromb Update. 2021 Jan 1;2:100026. 